Article

\title{
Superparamagnetic Nanoparticles with Efficient Near-Infrared Photothermal Effect at the Second Biological Window
}

\author{
Maria Antònia Busquets ${ }^{1,2}$ (D) Juan Marcos Fernández-Pradas ${ }^{2,3}$ (D), Pedro Serra ${ }^{2,3(1)}$ \\ and Joan Estelrich 1,2,* \\ 1 Department of Pharmacy, Pharmaceutical Technology and Physical Chemistry, Universitat de Barcelona, \\ Avda Joan XXIII, 27-31, 08028 Barcelona, Catalonia, Spain; mabusquetsvinas@ub.edu \\ 2 Institut de Nanociència i Nanotecnologia (IN $\left.{ }^{2} \mathrm{UB}\right)$, Universitat de Barcelona, \\ 08028 Barcelona, Catalonia, Spain; jmfernandez@ub.edu (J.M.F.-P.); pserra@ub.edu (P.S.) \\ 3 Department of Applied Physics, Universitat de Barcelona, Martí i Franquès 1, \\ 08028 Barcelona, Catalonia, Spain \\ * Correspondence: joanestelrich@ub.edu; Tel.: +34-934-024-559
}

Academic Editor: Matteo Calvaresi

Received: 4 September 2020; Accepted: 10 November 2020; Published: 14 November 2020

\begin{abstract}
Superparamagnetic nanoparticles (iron oxide nanoparticles-IONs) are suitable for hyperthermia after irradiating with radiofrequency radiation. Concerning the suitability for laser ablation, IONs present a low molar absorption coefficient in the near-infrared region close to $800 \mathrm{~nm}$. For this reason, they are combined with other photothermal agents into a hybrid composite. Here, we show that IONs absorb and convert into heat the infrared radiation characteristic of the so-called second-biological window (1000-1350 nm) and, in consequence, they can be used for thermal ablation in such wavelengths. To the known excellent water solubility, colloidal stability and biocompatibility exhibited by IONs, an outstanding photothermal performance must be added. For instance, a temperature increase of $36^{\circ} \mathrm{C}$ was obtained after irradiating at $8.7 \mathrm{~W} \mathrm{~cm}{ }^{-2}$ for $10 \mathrm{~min}$ a suspension of IONs at iron concentration of $255 \mathrm{mg} \mathrm{L}^{-1}$. The photothermal conversion efficiency was $\sim 72 \%$. Furthermore, IONs showed high thermogenic stability during the whole process of heating/cooling. To sum up, while the use of IONs in the first bio-window (700-950 nm) presents some concerns, they appear to be good photothermal agents in the second biological window.
\end{abstract}

Keywords: NIR; superparamagnetic nanoparticles; photothermal therapy; photothermal agents; biological windows

\section{Introduction}

Thermal therapy encompasses all therapeutic treatments based on conduction of heat into or out of a part of or the whole body [1]. The physiologic repercussion of this transfer of thermal energy is getting a temperature that is either colder or hotter than normal. Concerning the medical applications of hot temperatures, thermal therapy may be accomplished by two techniques, namely, hyperthermia-including long-term low-temperature hyperthermia with treatment for $6-72 \mathrm{~h}$ at $40-41{ }^{\circ} \mathrm{C}$ and moderate temperature hyperthermia with treatment for $15-60 \mathrm{~min}$ at $42-45^{\circ} \mathrm{C}$-and thermal ablation or high-temperature hyperthermia, with exposure to $>50{ }^{\circ} \mathrm{C}$ for $4-6 \mathrm{~min}$ [2]. Hyperthermia treatments are an approach of great interest, especially in oncology. Low and moderate-temperature hyperthermia results in changes in the physiology of the tissues that are for the most part reversible. For this reason, such treatment must be combined with other therapeutic approaches like radiation or chemotherapy to be a valid anti-cancer treatment. In contrast, thermal 
ablation produces more dramatic and irreversible changes as vascular stasis, protein denaturation, cellular coagulation and necrosis [3].

Thermal ablation requires the transformation of energy into heat. To this end, many different energy sources can be used: Radiofrequency, high-intensity focused ultrasonography, microwave, alternating magnetic field and laser [4]. Concerning the use of a laser, a photothermal interaction is produced by the transformation of photon energy (absorbed by tissue fluids) into heat energy that emanates from the molecular vibration and collisions between molecules. A portion of the vibrational energy of excited molecules is transferred to the colliding molecule as kinetic energy of translation. This transmission is manifested on the macroscopic scale as a temperature increase [5]. However, thermal ablation using a visible laser has been normally regarded as a non-reliable technique mainly for three reasons. First, the existence of the so-called heat-sink effect that depletes heat and weakens the power of the thermal effect. This effect hinders the treatment of lesions near large vascular structures using laser ablation alone [6]. Secondly, human tissues strongly absorb the radiation of the visible range of the electromagnetic spectrum; this fact limits any photothermal treatment to superficial tumors $[7,8]$. Furthermore, as both healthy and cancerous tissues can absorb the energy of a visible laser, damage in non-cancerous tissues is also possible. To solve these problems and increase the efficacy and selectivity of photothermal ablation induced by laser, it is imperative to use radiation at wavelengths with low absorption in tissues and include light-absorbing materials, the photothermal agents (PAs), in the tumor. Thus, controlling the incorporation of PA into tumors facilitates a high heat deposition in the tumor area at low laser intensities and thus minimizes the injury in the surrounding tissue [9]. Moreover, further diminution of non-desired light absorption by healthy tissues can be reached by using specific laser wavelengths belonging to the so-called biological windows [10].

Biological windows can be considered as the spectral ranges in which tissues become to a certain extent transparent due to a simultaneous reduction in both absorption and scattering. Within these windows, three singular wavelength regions have been established: The so-called first biological window that extends from $700 \mathrm{~nm}$ to $950 \mathrm{~nm}$. This window limits with the visible band and an absorption band at $980 \mathrm{~nm}$ due to the absorption of water. Skin, tissues and hemoglobin display minimal absorbance at this range. The second biological window covers the region from $1000 \mathrm{~nm}$ to $1350 \mathrm{~nm}$, both limits corresponding to water absorption bands. In this spectral region, optical absorption does not disappear thoroughly but, on the other hand, scattering is reduced because of the longer wavelengths. The third biological window is found from 1350 to $1870 \mathrm{~nm}$ and provides increased transparency toward biological matter [11]. The wavelengths of these biological windows belong to the near-infrared (NIR) range of the electromagnetic spectrum.

The simultaneous use of PA and lasers emitting radiation at wavelengths in the range of biological windows is the basis of the photothermal therapy (PTT). Unlike photodynamic therapy (PDT) which has an anticancer effect relying on the generation of radical oxygen species (ROS), PTT exerts its effect by increasing the temperature of the milieu [12]. In photothermal ablation induced by laser, the cancer treatment provided does relatively little damage to surrounding healthy tissues because the thermal effect is solely produced when NIR light is applied and only in the presence of a PA which transforms absorbed light into heat. An ideal PA should possess large absorption cross sections for optical wavelengths, have low toxicity and be soluble in biocompatible solutions [13].

Organic and inorganic materials can act as PA [14]. Among inorganic materials, some nanostructures are suitable as theranostic systems. For instance, magnetic nanostructures can display the dual functions of NIR absorption and magnetism. The magnetic property affords the capacity of being used as a magnetic resonance imaging (MRI) contrast agent, and the use of an external magnetic force facilitates the enrichment of the magnetic nanostructures in the desired local tumor regions, while they enable the conversion of NIR irradiation into heat for PTT.

Among magnetic nanoparticles with dual functions of NIR absorption and magnetism, iron oxide nanoparticles (IONs) attract attention as particles suitable for PTT. IONs can be prepared in different sizes and shapes by means of well-established and relatively cheap methodologies. IONs are biodegradable, 
biocompatible, relatively non-toxic and may be easily functionalized and tuned for specific applications. Iron oxide can be present in different chemical compositions, such as magnetite $\left(\mathrm{Fe}_{3} \mathrm{O}_{4}\right)$, maghemite $\left(\gamma-\mathrm{Fe}_{2} \mathrm{O}_{3}\right)$ or, most usually, a non-stoichiometric mixture of the two. Nanosized magnetite is known to naturally oxidize, at least partly, toward maghemite, thus getting to an unknown composition of the tested product [15]. Below specific sizes (25 nm for magnetite, $30 \mathrm{~nm}$ for maghemite), both oxides present superparamagnetism behavior; that is, in the presence of an external magnet superparamagnetic nanoparticles turn to magnetic, but return to a non-magnetic state when the external magnet is removed [16]. IONs can be easily degraded in vivo, where iron homeostasis is assumed by the iron-storage protein, ferritin $[17,18]$. Furthermore, IONs are excreted mainly by feces, thus indicating low damnification for organisms [19].

The crystalline structure of magnetite consists of a cubic inverse spinel. The face-centered cubic (fcc) unit cell (JCPDS 19-629) is composed of $32 \mathrm{O}$ anions, $16 \mathrm{Fe}$ (III) cations and $8 \mathrm{Fe}(\mathrm{II})$ cations. Half of the Fe(III) cations are tetrahedrally (tet) coordinated, while the other half and all of the Fe(II) ions are octahedrally (oct) coordinated, forming a unit cell of $\left(\mathrm{Fe}_{8}{ }^{3+}\right)_{\text {tet }}\left(\mathrm{Fe}_{8}{ }^{3+} \mathrm{F}_{\mathrm{e} 8}{ }^{2+}\right)_{\mathrm{oct}} \mathrm{O}_{32}$ [20]. $\mathrm{Fe}$ (II) and Fe(III) in the octahedral sites result in an intervalence charge transfer (IVCT) that rises to an absorption band at the second NIR region at 1000-1350 nm [21]. When magnetite becomes maghemite by oxidation, $\mathrm{Fe}^{2+}$ oct is oxidized to $\mathrm{Fe}^{3+}$ oct, producing vacancies restricted to the octahedral sites. In order to explain these vacancies, the unit cell for maghemite (JCPDS 39-1346) can be expressed as $\left(\mathrm{Fe}_{8}{ }^{3+}\right)_{\text {tet }}\left(\mathrm{Fe}_{40 / 3}{ }^{3+}\right.$ $\left.\square_{8 / 3}\right)_{\text {oct }} \mathrm{O}_{32}$ where $\square$ indicates a vacant site. Finally, it is important to remark that an outer coating of maghemite may develop at the particle-water interface during magnetite oxidation [22]. In this case, the non-stoichiometric structure of maghemite results in a loss of optical absorption in the NIR wavelengths regions [21].

IONs proved to be suitable for hyperthermia when they were irradiated with radiofrequency of $224 \mathrm{MHz}$ using a waveguide applicator [23]. Concerning the suitability for PTT, IONs possesses a low molar absorption coefficient in the NIR region, and thus an apparent poor photothermal efficacy. For this motive, usually they are associated with other PA forming a hybrid nanocomposite, especially with gold or with an organic compound [14]. However, IONs can be effective PAs themselves. It was demonstrated that the greatest part of the heat generated by magnetite nanoparticles was effectively dissipated to the surroundings without producing significant undesirable changes of the particles such as crystalline phase transitions, agglomeration or fragmentation [24]. Recently, the photothermal effectiveness of IONs has been proved to depend on particle size: The effectiveness shows a good correlation with particle volume [25]. Several works using aggregated or individual IONs as PA in the first biological window have been described [26-32]. In this way, Yuan et al. demonstrated that IONs coated with polyethylene glycol (PEG) presented anti-cancer activity [33]. However, to the best of our knowledge, there are only few studies on the photothermal therapy application of IONs in the second biological window [34,35].

The aim of the work here described was to show the photothermal properties of IONs illuminated with the radiation of the second biological window. There is growing interest in the second NIR window, which offers better light penetration, lower background signal and higher maximum permission exposure compared to the traditional first window [36]. Concretely, the NIR first window is not optimal because the auto-fluorescence of the tissues results in an important background noise, and the presence of photon scattering restricts the tissue penetration depth. It is known that photon scattering scales as $\lambda^{-\alpha}$, where $\lambda$ is the wavelength and $\alpha=0.2-4$ for biological tissues. In consequence, scattering is lesser if a radiation with longer wavelengths is used. The maximum permissible exposure (MPE) for skin is $1 \mathrm{~W} / \mathrm{cm}^{2}$ for a $1064 \mathrm{~nm}$ laser, compared with $0.3 \mathrm{~W} / \mathrm{cm}^{2}$ for a radiation of $808 \mathrm{~nm}$, according to the ANSI (American National Standard Institute) standard (ANSI Z 136.1 and Z 136.3 combination set: "Safe Use of Lasers and Safe Use of Lasers in Health Care Facilities"). The same Institute indicates that the exposure time can reach $3 \times 10^{4} \mathrm{~s}(\sim 1$ day). 


\section{Results and Discussion}

\subsection{Characterization of IONs}

IONs were synthesized by coprecipitation of iron salts in the presence of PEG. The obtained ferrofluid was characterized by X-ray diffraction (XRD), transmission electron microscopy (TEM), high-resolution TEM (HRTEM), dynamic light scattering (DLS), Doppler microelectrophoresis, thermogravimetric analysis (TGA) and content in iron.

Figure 1a shows the XRD measurement of the as-obtained ferrofluid. The observed relatively strong peaks at $2 \theta$ values of $29.98^{\circ}, 35.44^{\circ}, 42.94^{\circ}, 53.51^{\circ}, 56.82^{\circ}$ and $62.46^{\circ}$ were ascribed to the (111), (220), (311), (400), (511) and (440) planes of magnetite, which match well with the database of magnetite in the JCPDS (JCPDS card number 19-629).
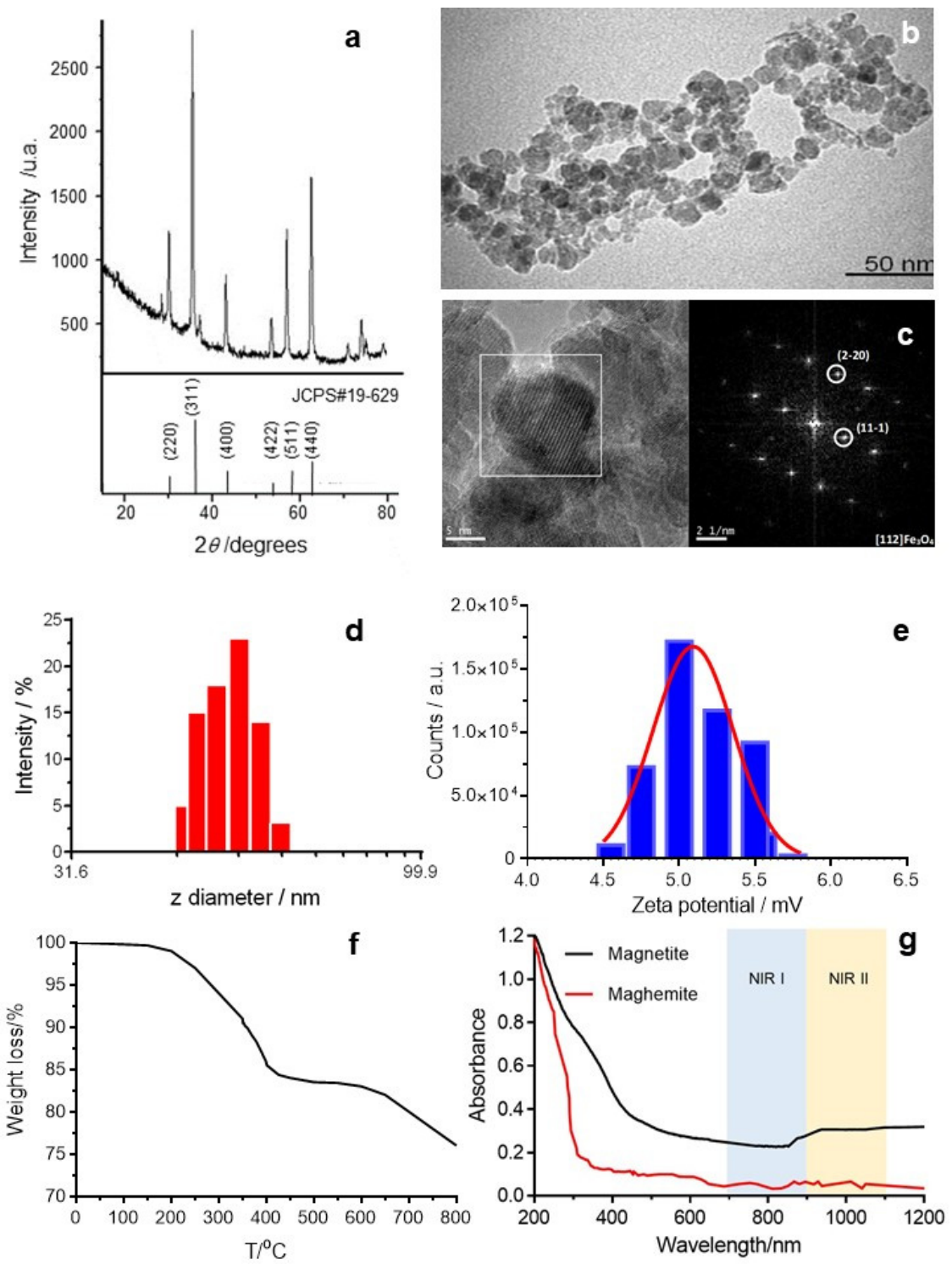

Figure 1. (a) X-ray diffraction (XRD) pattern, (b) transmission electron microscopy (TEM) image, (c) high-resolution (HR)-TEM images and the corresponding fast Fourier transform (FFT), (d) hydrodynamic radius of the as-prepared ferrofluid, (e) $\zeta$-potential, (f) thermogravimetric analysis (TGA) and (g) UV-Vis-near-infrared (NIR) absorption spectrum of a suspension of $4.5 \mathrm{mM}$ iron oxide nanoparticles (IONs) in water and after oxidation (maghemite at the same concentration). 
The mean crystal size $\left(\mathrm{D}_{\mathrm{hkl}}\right)$ is the crystallite size, the smaller monocrystall in the system. It is calculated by the Scherrer equation which relates the size to the broadening of a peak in the diffraction pattern. The Scherrer equation is given by:

$$
\mathrm{D}_{\mathrm{hkl}}=\frac{0.9 \lambda}{\beta \cos \theta}
$$

where $\lambda$ is the $X$-ray wavelength $(0.154056 \mathrm{~nm}), 0.9$ is a dimensionless shape factor, $\beta$ is the half-width of the most intense XRD peak, that is the peak at $2 \theta=35.44^{\circ}(0.01183 \mathrm{rad})$, and $\theta$ is the half-diffraction angle or Bragg angle $\left(17.72^{\circ}\right)$. The mean crystal size was found to be $12.3 \mathrm{~nm}\left(\mathrm{D}_{311}\right)$. The interplanar $\left(\mathrm{d}_{\mathrm{hkl}}\right)$ is the spacing between planes in a family with the Miller indexes $\mathrm{h}, \mathrm{k}$ and $\mathrm{l}$. At the plane (311) it can be obtained from:

$$
\mathrm{d}_{311}=\frac{\lambda}{2 \sin \theta}=0.2531 \mathrm{~nm}
$$

The lattice constant (a) for a cubic structure calculated from:

$$
\mathrm{d}_{\mathrm{hkl}}=\frac{\mathrm{a}}{\sqrt{\mathrm{h}^{2}+\mathrm{k}^{2}+\mathrm{l}^{2}}}
$$

was $0.8394 \mathrm{~nm}$.

Figure $1 \mathrm{~b}, \mathrm{c}$ shows the transmission electron microscopy (TEM) and high-resolution TEM (HRTEM) images, respectively, of the ferrofluid. The TEM image illustrates aggregated IONs while the HRTEM image shows their high crystallization behavior. The observed aggregation was due to the preparation of samples for TEM. In suspension, these nanoparticles are very stable. The primary particles were estimated as $13.3 \mathrm{~nm}$ in diameter with almost spherical shapes. Figure $1 \mathrm{~d}$ shows the size distribution in intensity of the IONs obtained by DLS. The z-average diameter was $54 \pm 13 \mathrm{~nm}$ (hydrodynamic diameter) and the polydispersity index (PI) was $0.10 \pm 0.06$. The nanoparticles presented a low surface charge at pH 6.5 ( $\zeta$-potential $\sim 5 \mathrm{mV}$ ) (Figure 1e) due to the hydroxyl groups of the PEG adsorbed onto the iron nanoparticle. A TGA curve performed over a temperature range of $160-450{ }^{\circ} \mathrm{C}$ gave a weight loss of $14.5 \%$ (Figure 1f). The loss of weight was a consequence of desorption and subsequent decomposition of PEG. The content in iron determined by inductively coupled plasma-optical emission spectrometry (ICP-OES) was $595 \mu \mathrm{g}$ of Fe by g of ferrofluid.

The excellent photothermal performance of IONs in the second biological window is due to the intervalence charge transfer (IVCT) transition that such nanoparticles possess. The charge-transfer transitions between $\mathrm{Fe}^{2+}$ and $\mathrm{Fe}^{3+}$ ions in magnetite provide an absorption band in the NIR region (Figure 1g). It is worth noting that this transition is not present in maghemite [21]. The absorption spectrum of IONs shows a dip in the 700-800 nm region, which covers the largest part of the first biological widow, but it increases considerably in the second biological window range [34,35].

Figure 2a presents the magnetization-magnetic field $(\mathrm{M}-\mathrm{H})$ plots at $300 \mathrm{~K}$ of IONs. They show a sharp slope and a lack of a hysteresis loop, pointing out superparamagnetic behavior. The saturation magnetization (Ms) was estimated to be $65 \mathrm{emu} \mathrm{g}^{-1}$ at $5 \mathrm{kOe}$, lower than of bulk $\mathrm{Fe}_{3} \mathrm{O}_{4}\left(77 \mathrm{emu} \mathrm{g}^{-1}\right)$ but concordant with the percentage of polymer coating the magnetite. According to the magnetization, we obtained a polymer coating of $15.6 \%$, similar to the $14.5 \%$ obtained by TGA. A magnetic squareness ratio (ratio between the remanent magnetization $\left(\mathrm{Mr}=0.98 \mathrm{emu} \mathrm{g}^{-1}\right.$ ) and the saturation magnetization) of 0.015 was obtained, indicating that these IONs are superparamagnetic at room temperature since any value $<0.5$ confirms the existence of a single domain. Moreover, a coercivity of $7 \mathrm{Oe}$ was observed (Figure 2b). This low value of coercivity indicates a low resistance of such material to becoming demagnetized. Concerning the temperature-dependent magnetization. Concerning zero-field-cooled-field-cooled (ZFC-FC) curves between 5 and $300 \mathrm{~K}$ at 50 Oe, the collected data of IONs are reported in Figure 2c. To create a ZFC curve, the sample was cooled to $5 \mathrm{~K}$ in the absence of a magnetic field. Then, a weak field (50 Oe) was applied and the sample slowly warmed. When the afforded thermal energy reached a value, individual spins started to align with the 
applied field. The alignment reached a maximum at $130 \mathrm{~K}$, the blocking temperature $\left(T_{\mathrm{B}}\right)$. After that temperature, the alignment decreased as a function of the inverse of the temperature as thermal energy exceeds the energy obtained by the alignment of the spins. $T_{\mathrm{B}}$ is well below room temperature pointing out that the synthesized IONs are superparamagnetic at physiological temperature as required for in vivo applications. The FC curve was produced at this point by re-cooling the sample in the presence of the same field. There was no hysteresis above $T_{\mathrm{B}}$ where the sample is superparamagnetic. At $T_{\mathrm{B}}$ the spins become blocked and unable to reorient themselves, and they keep in their maximally aligned state [37]. At a temperature lower than $T_{\mathrm{B}}$, the curves FC and ZFC separate each other, pointing out that the material shows ferromagnetic behavior. Figure $2 \mathrm{~d}$ shows the response of the ferrofluid to an external magnetic field.
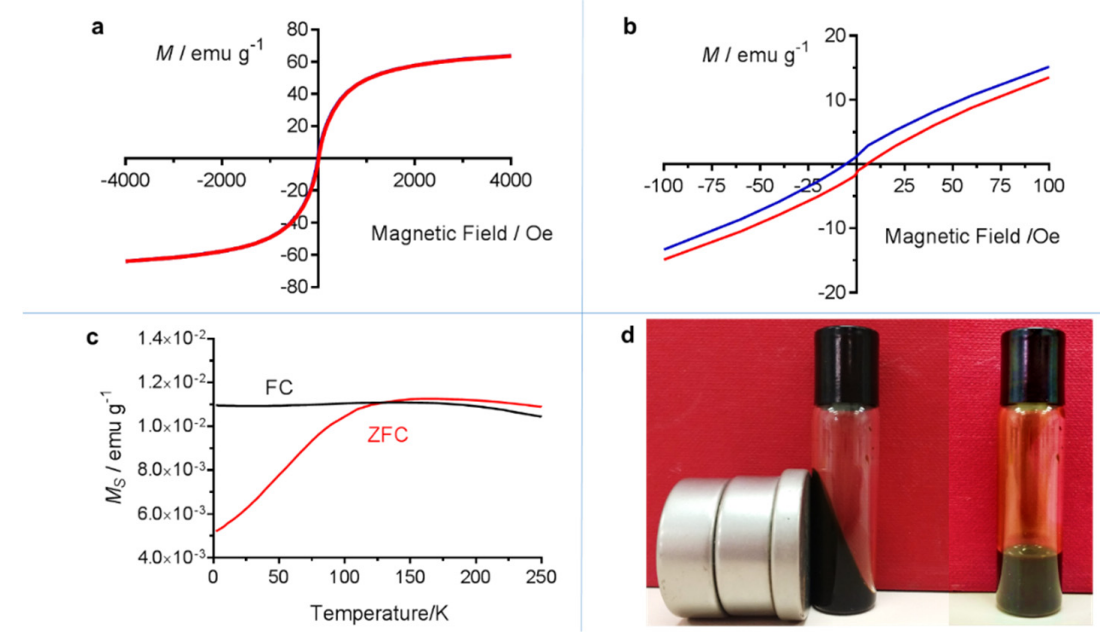

Figure 2. (a) Magnetization plot at $300 \mathrm{~K}$ of the as-prepared fluid; (b) Enlargement of the hysteresis loop of Figure 2a in the low field region; (c) Temperature-dependent ZFC-FC magnetization curves of the as-prepared ferrofluid measured at $50 \mathrm{Oe}$; (d) Effect of an external magnet on the ferrofluid.

\subsection{Photothermal Properties of IONs}

Photothermal effects of IONs were first tested in aqueous suspensions at three iron concentrations $\left(51,127.5\right.$ and $\left.255 \mathrm{mg} \mathrm{L}^{-1}\right)$ at three powers $\left(3.5,8.7\right.$ and $\left.14 \mathrm{~W} \mathrm{~cm}^{-2}\right)$. We used a total power laser relatively low (from $0.3 \mathrm{~W}$ to $1.3 \mathrm{~W}$ ) but these powers are applied on a small beam laser diameter $(3.6 \mathrm{~mm})$ and, for this reason, the resulting power densities are high. The $1064 \mathrm{~nm}$ laser beam was directed through the quartz cuvette with the different suspensions, and temperature measurements were obtained with the IR camera. The incident (as well as the transmitted) laser power was measured with a calibrated thermopile (Laserpoint model AHA-05-D20-BBF). The temperature increase was recorded along the sample for $10 \mathrm{~min}$. As can be seen in Figure 3, after a few minutes of irradiation there were small temperature differences along the measured area. The maximum recorded value in the area was chosen as the characteristic temperature for each time.

The photothermal effect of IONs in water upon laser irradiation was investigated at several iron concentrations and power densities of the $1064 \mathrm{~nm}$ laser. At any power density, an evident concentration-dependent temperature increase was observed (Figure 4a), whereas the pure water (double deionized water) showed slight changes in temperature, especially for the lowest power density $\left(1.5^{\circ} \mathrm{C}\right.$ at $\left.3.5 \mathrm{~W} \mathrm{~cm}^{-2}\right)$. It is important to remark that in the second spectral window, optical absorption does not disappear entirely (averaged water absorption coefficient is close to $0.5 \mathrm{~cm}^{-1}$ ) [13]. Concerning the samples, a temperature increase of $20.5^{\circ} \mathrm{C}$ was detected at the lowest concentration (51 mg L $\left.{ }^{-1}\right)$ within $10 \mathrm{~min}$, whereas at the high concentration $\left(255 \mathrm{mg} \mathrm{L}^{-1}\right)$ an increase of $35^{\circ} \mathrm{C}$ was recorded. This value was extremely significant in comparison with that obtained with pure water $\left(\sim 6.7^{\circ} \mathrm{C}\right)$. In the same manner, the temperature change of the IONs at a constant concentration $\left(51 \mathrm{mg} \mathrm{L}^{-1}\right.$ ) also showed laser power-dependent behavior (Figure $4 \mathrm{~b}$ ). The temperature of IONs 
increased up to $63.5^{\circ} \mathrm{C}$ at a power density of $14 \mathrm{~W} \mathrm{~cm}^{-2}, 51.5^{\circ} \mathrm{C}$ at a power density of $8.7 \mathrm{~W} \mathrm{~cm}^{-2}$ and $\sim 36^{\circ} \mathrm{C}$ at $3.5 \mathrm{~W} \mathrm{~cm}^{-2}$ within $10 \mathrm{~min}$ of laser irradiation. The temperatures reached after this time for all of the experiments carried out can be found in Table S1 of the Supplementary Materials. As expected, heating increased when exposing the samples at high power densities, and it also increased with the nanoparticle concentration. Available preclinical photothermal studies have used power densities up to $3-4 \mathrm{~W} / \mathrm{cm}^{2}[38,39]$. For biomedical applications, irradiation with high power density can be used at short exposure times to ablate tumoral zones or to obtain a rapid increase of temperature.

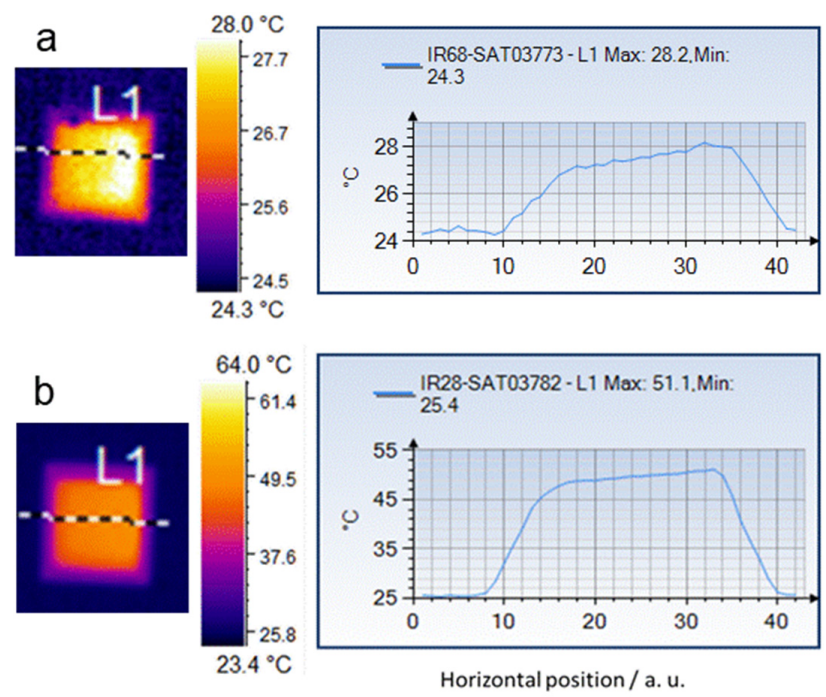

Figure 3. Thermal image acquired by the IR camera on (a) water and (b) the sample at $51 \mathrm{mg} \mathrm{mL}^{-1}$ concentration at the intermediate power $\left(8.7 \mathrm{~W} \mathrm{~cm}^{-2}\right)$ after $8 \mathrm{~min}$ of irradiation. The temperature measured at the cross-sectional L1 line (left) is recorded in the picture on the right. In this case, a maximal value of $28.2{ }^{\circ} \mathrm{C}$ and $51.1^{\circ} \mathrm{C}$ was obtained for water and the sample, respectively. The laser beam went from right to left through the center of the wall of the cuvette.
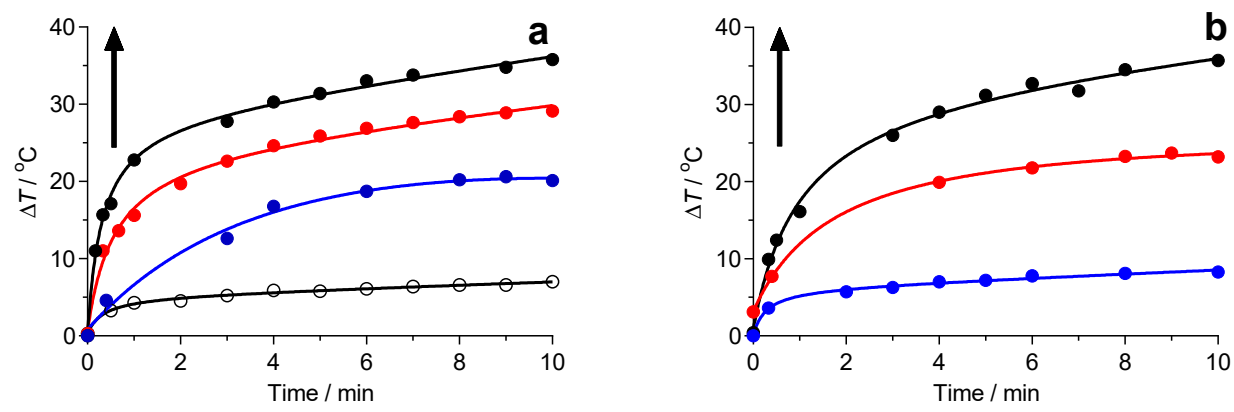

Figure 4. Plots of the temperature increase versus time during laser irradiation Concentration-dependent thermogenesis of IONs at (a) various concentrations at a power density of $8.7 \mathrm{~W} \mathrm{~cm}^{-2}$ (black dots: $255 \mathrm{mg} \mathrm{L}^{-1}$; red dots: $127.5 \mathrm{mg} \mathrm{L}^{-1}$; blue dots: $51 \mathrm{mg} \mathrm{L}^{-1}$; open dots: Water), and (b) at various laser power densities at an iron concentration of $51 \mathrm{mg} \mathrm{L}^{-1}$ (black dots: $14 \mathrm{~W} \mathrm{~cm}^{-2}$; red dots: $8.7 \mathrm{~W} \mathrm{~cm}^{-2}$; blue dots: $3.5 \mathrm{~W} \mathrm{~cm}^{-2}$ ).

To explore the photothermal stability of IONs, multiple cycles of laser irradiation were performed with an iron concentration of $127.5 \mathrm{mg} \mathrm{L}^{-1}$ at a power density of $8.7 \mathrm{~W} \mathrm{~cm}^{-2}$. After four continuous heating/cooling cycles, the changes in temperature were consistent (Figure 5a). From this plot, we can observe that IONs exhibit good thermogenic stability during the whole process. The temperature increased by around $30^{\circ} \mathrm{C}$ when the suspension was irradiated for $600 \mathrm{~s}$ and this increase did not vary significantly with further irradiation. The maximal temperature was achieved when an equilibrium between the heat input and output was reached. Contrary to the ferrofluid, the temperature of the control water increased by only $6.7^{\circ} \mathrm{C}$. Besides this photothermal property, IONs present great 
stability during photothermal heating at temperatures above $770 \mathrm{~K}$, displaying no change in size or crystallinity [24].

Using the heating profile of pure water, the $Q_{\text {dis }}$ was measured to be $0.319 \mathrm{~W}$. The cooling cycle obtained in the study of the photothermal stability of IONs was used to determine the rate of heat transfer from the IONs to the environment. Figure $5 b$ displays the temperature decay when IONs are under the cooling period after the irradiation of the sample for $10 \mathrm{~min}$. Mathematically, the temperature follows an exponential decay equation that is deduced from the energy balance when there is no heat input:

$$
T=T_{a m b}+\left(T_{\max }-T_{a m b}\right) e^{-\frac{t}{\tau_{s}}}
$$

where $t=0$ is assigned when the temperature is $T_{\max }$; $T_{a m b}$ is the room temperature. By fitting the values of the temperature decays shown in Figure $5 \mathrm{a}$, the time constant $\tau s$ of $220 \mathrm{~s}$ was determined.
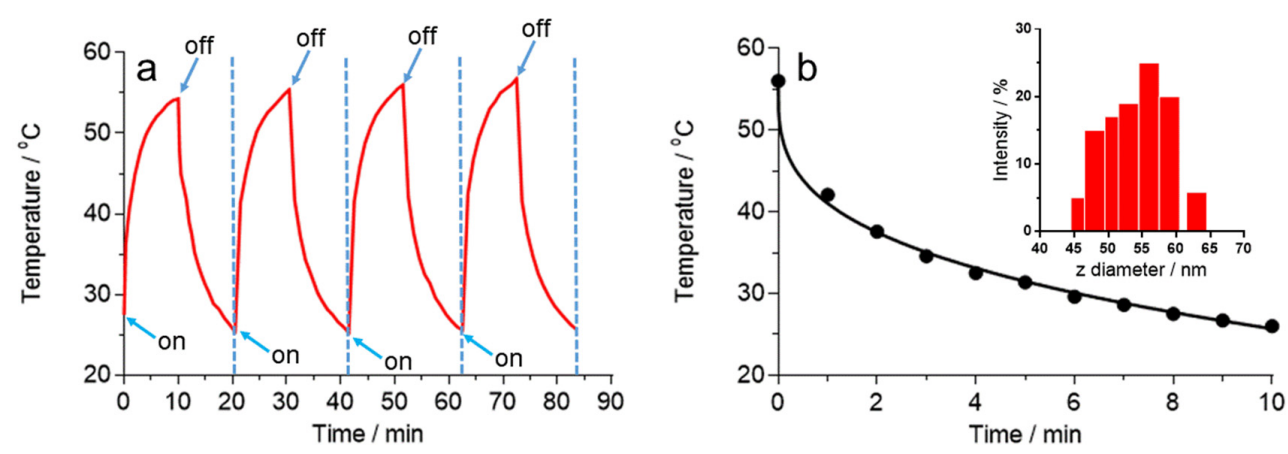

Figure 5. Photothermal stability of IONs. (a) Plot of temperature change of the IONs in water over four on/off cycles of $1064 \mathrm{~nm}$ laser irradiation; the temperature increased from an ambient value of $25{ }^{\circ} \mathrm{C}$ to an equilibrium value of $56^{\circ} \mathrm{C}$ during continuous irradiation for $600 \mathrm{~s}$. (b) Plot of temperature decay during the cooling period. Inset: Size distribution of IONs after being submitted to the four irradiation cycles.

Photothermal conversion efficiency $(\eta)$, determined according to Equation (5), is an essential parameter for the assessment of any photothermal agent. The heat transfer factor $h S$ was evaluated and a value of $25 \pm 1 \mathrm{~mW} \mathrm{~K}^{-1}$ was obtained.

The calculated $\eta$ values were $76 \%, 70 \%$ and $80 \%$ for $255 \mathrm{mg} \mathrm{L}^{-1}, 127.5 \mathrm{mg} \mathrm{L}^{-1}$ and $51 \mathrm{mg} \mathrm{L}^{-1}$ of iron, respectively (average $\eta=75.3 \pm 5.0$ ) (Figure S1). These values demonstrate that IONs present a good photothermal performance in the second biological window. It is known that IONs possess low molar absorption coefficient in the first biological window $\left(15 \mathrm{M}^{-1} \mathrm{~cm}^{-1}\right.$ at $\left.808 \mathrm{~nm}\right)$ and, in consequence, their photothermal performance is poor. In contrast, we have determined a molar absorption coefficient of $182 \mathrm{M}^{-1} \mathrm{~cm}^{-1}$ at $1064 \mathrm{~nm}$ (Figure S1). Moreover, the photothermal effectiveness of IONs is dependent upon particle size, since the molar absorption coefficient increases with material size. In this way, Shen et al. have reported that clustered IONs were more efficient that the individual IONs in increasing the temperature at $808 \mathrm{~nm}$ [26]. The IONs used here $(13.3 \mathrm{~nm})$ can be considered as superparamagnetic particles of high size. Johnson et al. have proved by experiments and simulation that the heating ability is related to the volume of the nanoparticles, rather than the absorptivity of the particles. This dependence is associated to the fact that particles with larger heat capacities can heat larger volumes of their surrounding media for larger periods [25].

\section{Materials and Methods}

\subsection{Materials}

Ferric chloride hexahydrate $\left(\mathrm{FeCl}_{3} \cdot 6 \mathrm{H}_{2} \mathrm{O}\right)$ and ferrous chloride tetrahydrate $\left(\mathrm{FeCl}_{2} \cdot 4 \mathrm{H}_{2} \mathrm{O}\right)$ were purchased from Sigma-Aldrich (St. Louis, MO, USA). Polyethylene glycol (PEG) $\left(\mathrm{Mn}=4000 \mathrm{~g} \mathrm{~mol}^{-1}\right)$ was obtained from VWR International (Barcelona, Spain). Ammonium hydroxide $\left(\mathrm{NH}_{4} \mathrm{OH}, 25 \%\right)$ 
was purchased from Panreac (Barcelona, Spain). Deionized Millipore Milli-Q water was used in all experiments. A strong neodymium-iron-boron $\left(\mathrm{Nd}_{2} \mathrm{Fe}_{12} \mathrm{~B}\right)$ magnet $(1.2 \mathrm{~T})$ was obtained from Halde GAC (Barcelona, Spain).

\subsection{Synthesis of IONs}

IONS coated with PEG were prepared by coprecipitation of iron salts according to the reported method [40]. In this case, $3 \mathrm{~g}$ of PEG was added to a volume of $5 \mathrm{~mL}$ of water. After dissolving the polymer, $0.435 \mathrm{~g}$ of $\mathrm{FeCl}_{3} \cdot 6 \mathrm{H}_{2} \mathrm{O}$ and $0.16 \mathrm{~g}$ of $\mathrm{FeCl}_{2} \cdot 4 \mathrm{H}_{2} \mathrm{O}\left(2: 1\right.$ molar ratio of $\left.\mathrm{FeCl}_{3} / \mathrm{FeCl}_{2}\right)$ were added. When the iron salts and PEG were well dissolved, a solution $(10 \mathrm{~mL})$ of a $0.75 \mathrm{M} \mathrm{NH}_{4} \mathrm{OH}$ was added under intense mechanical stirring at a speed of $0.6 \mathrm{~mL} \mathrm{~min}{ }^{-1}$. The resulting ferrofluid was washed, collected with an external magnetic field and sonicated. Maghemite was obtained by boiling IONs with a solution of $0.8 \mathrm{~mol}$ of ferric nitrate for $30 \mathrm{~min}$.

\subsection{Characterization of IONs}

The crystalline phase of the coated nanoparticles was identified by X-ray diffraction (XRD) using a Bragg-Brentano $\theta / 2 \theta$ Siemens D-500 diffractometer (radius $=215.5 \mathrm{~mm}$ ) equipped with a $\mathrm{Cu} \mathrm{K} \alpha$ radiation source. The morphology of nanoparticles was observed by transmission electron microscopy (TEM) with a Jeol 1010 microscope and an HR-TEM Jeol 2010F microscope (Jeol, Japan) operating at an accelerating voltage of $80 \mathrm{kV}$ and $200 \mathrm{kV}$, respectively. Images were recorded with a Megaview III camera, and the acquisition was accomplished with Soft-Imaging software (SIS, Germany). The hydrodynamic diameter of nanoparticles was determined by dynamic light scattering (DLS) at a fixed scattering angle of $90^{\circ}$ with a Zetasizer Nano (Malvern, United Kingdom) at $25^{\circ} \mathrm{C}$. To perform this measurement, nanoparticles from the stock solution were dispersed in distillated water until $0.1 \mathrm{~g} \mathrm{~L}^{-1}$ solid content. Particle size distribution was determined by the polydispersity index (PI); this value ranges from 0.0 for an entirely monodisperse sample to 1.0 for a polydisperse sample. Absorption spectrum was obtained across the UV/Vis/NIR range (Perkin Elmer Lambda 950, Waltham, MA, USA). The iron concentration of the nanoparticles was determined with an inductively coupled plasma optical emission spectroscope (ICP-OES, Perkin Elmer model Optima 3200RL, USA). Isothermal magnetization was determined in a superconducting quantum interference device (SQUID) magnetometer (Quantum design MPMS XL) at $300 \mathrm{~K}$. For this determination, a few milligrams of the sample were lyophilized and the external magnetic field was swept from +5000 to -5000 Oe, and then back to +5000 Oe. The saturation magnetization values were normalized to the mass of nanoparticles to yield the specific magnetization, $M_{\mathrm{S}}\left(\mathrm{emu} \mathrm{g}^{-1}\right)$. Temperature-dependent curves were obtained after first cooling samples from $300 \mathrm{~K}$ in zero field applying 50 Oe (zero-field cooled [ZFC] curve), and then performing measurements upon warming (field-cooled [FC] curve). The content of PEG coating the iron oxide nanoparticles was determined by thermogravimetric analysis (TGA) using a TGA/SDTA851e (Mettler Toledo) with a $10^{\circ} \mathrm{C} / \mathrm{min}$ heating rate under nitrogen atmosphere $\left(50 \mathrm{~mL} \mathrm{~min}^{-1}\right)$. The measurement was taken from room temperature up to $800{ }^{\circ} \mathrm{C}$. The $\zeta$-potential of nanoparticles was measured by Doppler microelectrophoresis using a Zeta Sizer Nano ZS (Malvern, United Kingdom).

\subsection{Photothermal Properties of IONs}

IONs with different iron concentrations $\left(51,127.5\right.$ and $255 \mathrm{mg} \mathrm{L}^{-1}$, equivalent to $0.91,2.25$ and $4.5 \mathrm{mM})$ dispersed in water $(3.0 \mathrm{~mL})$ were poured in quartz cuvettes (total volume of $4.0 \mathrm{~mL}$ ) and irradiated by a collimated beam (spot size $10.2 \mathrm{~mm}^{2}$ ) of a continuous-wave Nd:YAG laser with a center wavelength of $1064 \mathrm{~nm}$ for $10 \mathrm{~min}$ (Basel Lasertech LBI6000). The temperature of the sample was recorded with an IR thermal camera G90 (Satir, Dogheda, Ireland). Water was used as the control. To evaluate the influence on the power density on the increase of temperature, the same ION suspensions were irradiated for $10 \mathrm{~min}$ with the different power densities of 3.5, 8.7 and $14 \mathrm{~W} / \mathrm{cm}^{2}$, respectively. The photothermal stability of IONs was also investigated. An ION suspension with iron 
concentration of $127.5 \mathrm{mg} \mathrm{L}^{-1}$ was irradiated with the NIR laser for $10 \mathrm{~min}$, followed by turning off the laser for cooling the sample to room temperature. This cycle was repeated four times. To determine the photothermal conversion efficiency $(\eta)$ of IONs, a suspension of $127.5 \mathrm{mg} \mathrm{L}^{-1}$ was continuously irradiated with the above laser until reaching a steady temperature, and then the laser was turned off. After that, the suspension was allowed to naturally cool to room temperature.

The photothermal conversion efficiency was determined using the following equation:

$$
\eta=\frac{h S\left(T_{\max }-T_{a m b}\right)-Q_{d i s}}{I\left(1-10^{-A}\right)}
$$

where $h$ is the heat transfer coefficient, $S$ is the surface area of the heat transfer to the surroundings, $T_{\max }$ is the maximum equilibrium temperature, $T_{a m b}$ is the ambient temperature of the surroundings, $I$ is the laser power, $A$ is the absorbance of PA at the emission wavelength of the laser, that is $1064 \mathrm{~nm}$, and $Q_{\text {dis }}$ is the heat dissipated from the light absorbed by the solvent and the container. It was measured using a quartz cuvette cell containing only double deionized water. The term $h S$ is determined by fitting the rate of temperature change when the laser is on to:

$$
T=T_{a m b}+\frac{Q_{i}}{h S}\left(1-e^{-\frac{t}{\tau_{s}}}\right)
$$

where $Q_{i}$ is the laser power absorbed in the sample, $t$ is the time at which the temperature $T$ is reached, and $\tau s$ is the time constant obtained from the cooling period after irradiating the sample [41].

\section{Conclusions}

We prepared PEG-coated magnetite nanoparticles (IONs) by an aqueous method under ambient conditions. Such non-functionalized IONs can be used as PAs in the second biological window themselves since they are able to absorb NIR radiation at $1064 \mathrm{~nm}$ at iron concentrations from 51 to $255 \mathrm{mg} \mathrm{L}^{-1}$ and transform it into heat, assessing the excellent photothermal conversion behavior of IONs. Moreover, the scattering that nanoparticles provoke at the second biological window is lower than in the shorter wavelengths. Hence, the efficiency of IONs in PTT is demonstrated, concretely in the second biological window. To the great potential of IONs to be used as PA, the nanoparticles add their low toxicity, as well as their easy degradation in vivo, where iron homeostasis is assumed by the iron-storage protein, ferritin. In conclusion, IONs are promising photothermal agents in the second biological window.

Supplementary Materials: The following are available online. Figure S1: Plot of the photothermal conversion efficiency with respect to iron molar concentration, Figure S2: Plot of the absorbance at $1064 \mathrm{~nm}$ with respect to iron molar concentration, and Table S1: Values of temperature reached after $10 \mathrm{~min}$ of irradiation at three power densities and three concentrations.

Author Contributions: M.A.B. and J.E. conceived and designed the experiments; M.A.B. performed the synthesis and characterization of magnetic nanoparticles; J.M.F.-P. and P.S. performed the laser experiments; J.E. wrote the original draft. M.A.B., J.M.F.-P. and P.S. revised the manuscript. All authors have read and agreed to the published version of the manuscript.

Funding: This research received no external funding.

Conflicts of Interest: The authors declare no conflict of interest.

\section{References}

1. Habash, R.W.; Bansal, R.; Kreski, D.; Alhafid, H.T. Thermal therapy, part 1: An introduction to thermal therapy. Crit. Rev. Biomed. Eng. 2006, 34, 459-489. [CrossRef] [PubMed]

2. Stauffer, P.R.; Goldberg, S.N. Introduction: Thermal ablation therapy. Int. J. Hyperth. 2014, 20, 671-677. [CrossRef] [PubMed]

3. Melamed, J.R.; Edelstein, R.S.; Day, E.S. Elucidating the fundamental mechanisms of cell death triggered by photothermal therapy. ACS Nano 2015, 9, 6-11. [CrossRef] [PubMed] 
4. Melancon, M.P.; Elliott, A.; Ji, X.; Shetty, A.; Yang, Z.; Tian, M.; Taylor, B.; Stafford, R.J.; Li, C. Theranostics with multifunctional magnetic gold nanoshells: Photothermal therapy and $\mathrm{t} 2 *$ magnetic resonance imaging. Investig. Radiol. 2011, 46, 132-140. [CrossRef] [PubMed]

5. Jelínková, H. Introduction: The history of lasers in medicine. In Lasers for Medical Applications: Diagnostics, Therapy and Surgery; Jelínková, H., Ed.; Woodhead: Philadelphia, PA, USA, 2013; p. 832.

6. Frerichs, B.B.; Ritz, J.P.; Albrecht, T.; Valdeig, S.; Schenk, A.; Wolf, K.J.; Lehmann, K. Influence of intrahepatic vessels on volume and shape of percutaneous thermal ablation zone: In vivo evaluation in a porcine model. Investig. Radiol. 2008, 43, 211-218. [CrossRef] [PubMed]

7. Huang, X.; El-Sayed, I.H.; Qian, W.; El-Sayed, M.A. Cancer cell imaging and photothermal therapy in the near-infrared region by using gold nanorods. J. Am. Chem. Soc. 2006, 128, 2115-2120. [CrossRef] [PubMed]

8. Huang, X.; Jain, P.K.; El-Sayed, I.H.; El-Sayed, M.A. Plasmonic photothermal therapy (PPTT) using gold nanoparticles. Lasers Med. Sci. 2008, 23, 217-228. [CrossRef]

9. Jain, P.K.; Huang, X.; El-Sayed, I.H.; El-Sayed, M.A. Noble metals on the nanoscale: Optical and photothermal properties and some applications in imaging, sensing, biology, and medicine. Acc. Chem. Res. 2008, 41, 1578-1586. [CrossRef]

10. Weissleder, R.A. Clearer vision for in vivo imaging. Nat. Biotechnol. 2001, 19, 316-317. [CrossRef]

11. Hemmer, E.; Benayas, A.; Légaré, F.; Vetrone, F. Exploiting the biological windows: Current perspectives on fluorescent bioprobes emitting above $1000 \mathrm{~nm}$. Nanoscale Horizons 2016, 1, 168-184. [CrossRef]

12. Dougherty, T.J.; Gomer, C.J.; Henderson, B.W.; Jori, G.; Kessel, D.; Korbelik, M.; Moan, J.; Peng, Q. Photodynamic therapy. J. Natl. Cancer Inst. 1998, 90, 889-905. [CrossRef] [PubMed]

13. Jaque, D.; Maestro, L.M.; Del Rosal, B.; Haro-Gonzalez, P.; Benayas, A.; Plaza, J.L.; Rodriguez, E.M.; Sole, J.G. Nanoparticles for photothermal therapies. Nanoscale 2014, 6, 9494-9530. [CrossRef] [PubMed]

14. Estelrich, J.; Busquets, M.A. Iron oxide nanoparticles in photothermal therapy. Molecules 2018, $23,1567$. [CrossRef] [PubMed]

15. Da Costa, G.M.; Blanco-Andujar, C.; De Grave, E.; Pankhurst, Q.A. Magnetic nanoparticles for in vivo use: A critical assessment of their composition. J. Phys. Chem. B 2014, 118, 11738-11746. [CrossRef]

16. Estelrich, J.; Escribano, E.; Queralt, J.; Busquets, M.A. Iron oxide nanoparticles for magnetically-guided and magnetically-responsive drug delivery. Int. J. Mol. Sci. 2015, 16, 8070-8101. [CrossRef]

17. Volatron, J.; Carn, F.; Kolosnjaj-Tabi, J.; Javed, Y.; Vuong, Q.L.; Gossuin, Y.; Ménager, C.; Luciani, N.; Charron, G.; Hémadi, M.; et al. Ferritin protein regulates the degradation of iron oxide nanoparticles. Small 2016, 13, 1602030. [CrossRef]

18. Volatron, J.; Kolosnjaj-Tabi, J.; Javed, Y.; Vuong, Q.L.; Gossuin, Y.; Neveu, S.; Luciani, N.; Hémadi, M.; Carn, F.; Alloyeau, D.; et al. Physiological remediation of cobalt ferrite nanoparticles by ferritin. Sci. Rep. 2016, 7, 40075. [CrossRef]

19. Zhang, X.; Xu, X.; Li, T.; Lin, M.; Lin, X.; Zhang, H.; Sun, H.; Yang, B. Composite photothermal platform of polypyrrole-enveloped $\mathrm{Fe}_{3} \mathrm{O}_{4}$ nanoparticle self-assembled superstructures. ACS Appl. Mater. Interfaces 2014, 6, 14552-14561. [CrossRef]

20. Cornell, R.M.; Schwertmann, U. The Iron Oxides: Structure, Properties, Reactions, Occurrence and Uses; Wiley-VCH: Weinheim, Germany, 1996.

21. Tang, J.; Myers, M.; Bosnick, K.A.; Brus, L.E. Magnetite $\mathrm{Fe}_{3} \mathrm{O}_{4}$ nanocrystals: Spectroscopic observation of aqueous oxidation kinetics. J. Phys. Chem. B 2003, 107, 7501-7506. [CrossRef]

22. Rebodos, R.L.; Vikesland, P.J. Effects of oxidation on the magnetization of nanoparticulate magnetite. Langmuir 2010, 26, 16745-16753. [CrossRef]

23. Trujillo-Romero, C.J.; García-Jimeno, S.; Vera, A.; Leija, L.; Estelrich, J. Using nanoparticles for enhancing the focusing heating effect of an external waveguide applicator for oncology hyperthermia: Evaluation in muscle and tumor phantoms. Prog. Electromagn. Res. B 2011, 121, 343-363. [CrossRef]

24. Johnson, R.J.; Haas, K.M.; Lear, B.J. $\mathrm{Fe}_{3} \mathrm{O}_{4}$ nanoparticles as robust photothermal agents for driving high barrier reactions under ambient conditions. Chem. Commun. 2015, 51, 417-420. [CrossRef] [PubMed]

25. Johnson, R.J.G.; Schultz, J.D.; Lear, B.J. Photothermal effectiveness of magnetite nanoparticles: Dependende upon particle size probed by experiment and simulation. Molecules 2018, 23, 23051234. [CrossRef] [PubMed]

26. Shen, S.; Wang, S.; Zheng, R.; Zhu, X.; Jiang, X.; Fu, D.; Yang, W. Magnetic nanoparticle clusters for photothermal therapy with near-infrared irradiation. Biomaterials 2015, 39, 67-74. [CrossRef] 
27. Guo, X.; Li, W.; Luo, L.; Wang, Z.; Li, Q.; Kong, F.; Zhang, H.; Yang, J.; Zhu, C.; Du, Y.; et al. External magnetic field-enhanced chemo-photothermal combination tumor therapy via iron oxide nanoparticles. ACS Appl. Mater. Interfaces 2017, 9, 16581-16593. [CrossRef]

28. Guo, X.; Wu, Z.; Li, W.; Wang, Z.; Li, Q.; Kong, F.; Zhang, H.; Zhu, X.; Du, Y.P.; Jin, Y.; et al. Appropriate size of magnetic nanoparticles for various bioapplications in cancer diagnostics and therapy. ACS Appl. Mater. Interfaces 2016, 8, 3092-3106. [CrossRef]

29. Han, X.; Deng, Z.; Yang, Z.; Wang, Y.; Zhu, H.; Chen, B.; Cui, Z.; Ewing, R.C.; Shi, D. Biomarkerless targeting and photothermal cancer cell killing by surface-electrically-charged superparamagnetic $\mathrm{Fe}_{3} \mathrm{O}_{4}$ composite nanoparticles. Nanoscale 2017, 9, 1457-1465. [CrossRef]

30. Espinosa, A.; Di Corato, R.; Kolosnjaj-Tabi, J.; Flaud, P.; Pellegrino, T.; Wilhelm, C. Duality of iron oxide nanoparticles in cancer therapy: Amplification of heating efficiency by magnetic hyperthermia and photothermal bimodal treatment. ACS Nano 2017, 10, 2436-2446. [CrossRef]

31. Cazares-Cortes, E.; Nerantzaki, M.; Fresnais, J.; Wilhelm, C.; Grifette, N.; Ménager, C. Magnetic nanoparticles create hot spots in polymer matrix for controlled drug release. Nanomaterials 2018, 8, 850. [CrossRef]

32. Kolosnjaj-Tabi, J.; Kralj, S.; Griseti, E.; Nemec, S.; Wilhelm, C.; Plan Sangnier, A.; Bellard, E.; Fourquaux, I.; Golzio, M.; Rois, M.-P. Magnetic silica-coated iron oxide nanochains as photothermal agents disrupting the extracellular matrix, and eradicating cancer cells. Cancers 2019, 11, 2040. [CrossRef]

33. Yuan, G.; Yuan, Y.; Xu, K.; Luo, Q. Biocompatible PEGylated $\mathrm{Fe}_{3} \mathrm{O}_{4}$ nanoparticles as photothermal agents for near-infrared light modulated cancer therapy. Int. J. Mol. Sci. 2014, 15, 18776-18788. [CrossRef] [PubMed]

34. Huang, C.C.; Chang, P.Y.; Liu, C.L.; Xu, J.P.; Wu, S.P.; Kuo, W.C. New insight on optical and magnetic $\mathrm{Fe}_{3} \mathrm{O}_{4}$ nanoclusters promising for near infrared theranostic applications. Nanoscale 2015, 7, 12689-12697. [CrossRef] [PubMed]

35. Cabana, S.; Curcio, A.; Michel, A.; Wilhelm, C.; Abou-Hassan, A. Iron oxide mediated photothermal thearapy in the second biological window: A comparative study between magnetite/maghemite nanospheres and nanoflowers. Nanomaterials 2020, 10, 1548. [CrossRef] [PubMed]

36. Zhou, J.; Jiang, Y.; Hou, S.; Upputuri, P.K.; Wu, D.; Li, J.; Wang, P.; Zhen, X.; Pramanik, M.; Pu, K.; et al. Compact plasmonic blackbody for cancer theranosis in the near-infrared II window. ACS Nano 2017, 12, 2643-2651. [CrossRef] [PubMed]

37. Huber, D.L. Iron nanoparticles. Small 2005, 5, 482-501. [CrossRef]

38. Gobin, A.M.; Lee, M.H.; Halas, N.J.; James, W.D.; Drezek, R.A.; West, J.L. Near-infrared resonant nanoshells for combined optical imaging and photothermal cancer therapy. Nano Lett. 2007, 7, 1924-1931. [CrossRef]

39. Schwartz, J.A.; Shetty, A.M.; Price, R.E.; Stafford, R.J.; Wang, J.C.; Uthamanthil, R.K.; Pham, K.; McNichols, R.J.; Coleman, C.I.; Payne, J.D. Feasibility study of particle-assisted laser ablation of brain tumors in orthotopic canine model. Cancer Res. 2009, 69, 1659-1667. [CrossRef]

40. García-Jimeno, S.; Estelrich, J. Ferrofluid based on polyethylene glycol-coated iron oxide nanoparticles: Characterization and properties. Colloids Surf. A 2013, 420, 74-81. [CrossRef]

41. Roper, D.K.; Ahn, W.; Hoepfner, M. Microscale heat transfer transduced by surface plasmon resonant gold nanoparticles. J. Phys. Chem. C Nanomater. Interfaces 2007, 111, 3636-3641. [CrossRef]

Sample Availability: Samples of the compounds are not available from the authors.

Publisher's Note: MDPI stays neutral with regard to jurisdictional claims in published maps and institutional affiliations.

(C) 2020 by the authors. Licensee MDPI, Basel, Switzerland. This article is an open access article distributed under the terms and conditions of the Creative Commons Attribution (CC BY) license (http://creativecommons.org/licenses/by/4.0/). 